Marquette University

e-Publications@Marquette

Psychology Faculty Research and Publications

Psychology, Department of

$12-1-2012$

Experiencing Sexism and Young Women's Body Esteem

Debra Oswald

Marquette University, debra.oswald@marquette.edu

Stephen L. Franzoi

Marquette University, stephen.franzoi@marquette.edu

Katherine Frost

Marquette University, katherine.frost@marquette.edu

Accepted version. Journal of Social and Clinical Psychology, Vol. 31, No. 10 (December 2012):

1112-1137. DOI. (C) 2012 Guilford Press. Used with permission. 
Running head: BODY ESTEEM, AMBIVALENT SEXISM, BENEVOLENT SEXISM

Experiencing Sexism and Young Women's Body Esteem

Debra L. Oswald, Stephen L. Franzoi, Katherine A. Frost

Marquette University

Correspondence should be sent to Debra L. Oswald or Stephen L. Franzoi, Department of

Psychology, Cramer Hall, Marquette University, Milwaukee, WI 53201-1881. phone: 414-288-

3720 or 414-288-1650; e-mail: Debra.Oswald@ marquette.edu or

Stephen.Franzoi@marquette.edu

The authors would like to thank Catherine Byrne, Michaela Engdahl, Lucie Holmgreen, Dane Whicker, and Kathy Wierzchowski, for their assistance with data collection. 


\begin{abstract}
This two-study investigation examined the relationship between sexist attitudes and experiences with young women's body esteem. Specifically, we examined whether young women's body esteem was related to their own and their parents' endorsements of benevolent and hostile sexist beliefs and also whether women's body esteem was related to their actual everyday experiences with benevolent and hostile sexism. In Study 1, fathers' endorsement of benevolently sexist beliefs was positively correlated with daughters' weight-related and physical condition body esteem. No similar evidence was found for mothers or for either parent's endorsements of hostile sexist beliefs. In Study 2, young women's body esteem was positively related to their benevolently sexist experiences and negatively related to their hostile sexist experiences. These findings are consistent with ambivalent sexism theory. The results are discussed for their clinical and theoretical implications.
\end{abstract}

Key Words: body esteem, sexism 


\section{Experiencing Sexism and Young Women's Body Esteem}

Body image is the set of beliefs we have about our physical selves, and body esteem encompasses our attitudes toward our bodies. Women's body esteem is based on their assessment of three distinct dimensions related to their weight, physical condition, and sexual attractiveness (Franzoi \& Shields, 1984). American culture, like many around the world, places a premium on feminine physical attractiveness and, as a result, women frequently express concerns about being rejected based on their appearance (Park, 2007; Park, DiRaddo, \& Calogero, 2009). Beginning in late childhood and early adolescence, girls not only experience more dissatisfaction with their bodies than do boys, but they also experience a steady increase in this dissatisfaction over time (Feingold \& Mazzella, 1998; Martin, 2007). Furthermore, weight and overall body appearance concerns can become an obsession, negatively impacting women's mental and physical health (Grogan, 2008; Tiggemann, 2010).

As women's discontent with their bodies has become normative in American culture, researchers and clinicians have sought to identify factors that may underlay this problem. To date, there has been a focus on sociocultural factors such as the media's portrayal of the feminine beauty ideal (e.g., Dittmar, 2009; Franzoi, Vasquez, Sparapani, Frost, Martin, \& Aebly, 2012; Grabe, Ward, \& Hyde, 2008; Polivy \& Herman, 2004; Tiggeman \& McGill, 2004) as well as pressure to match that ideal from family (e.g., Clarke \& Griffin, 2007; Coomber \& King, 2008; Ferguson, Munoz, Contreras, \& Velasquez, 2011), and perception of peers' weight-related attitudes, "fat talk," and dieting behaviors (e.g., Britton, Martz, Bazzini, Curtin, \& LeaShomb, 2006; Gapinski, Brownell, \& LaFrance, 2003; Gravener, Haedt, Heatherton, \& Keel, 2008). Other researchers have investigated internalization of the beauty ideal (e.g., Brown \& Dittmar, 2005; Dittmar \& Howard, 2004) and personality traits related to perfectionism, psychological 
control, and the drive for thinness (e.g., Bruch, 1973; Gravener et al., 2008) as risk factors for body dissatisfaction and eating disorders.

What is sometimes forgotten when considering these possible determinants of body esteem is that they exist within a larger context of gender inequality. We propose that a crucial underlying factor for women's body esteem issues is pervasive and continuing sexism that is so thoroughly embedded within our culture that it is often an integral part of gender socialization within the family and experienced by women daily. In two studies we examine how culturalbased sexism, expressed both as hostility and paternalistic benevolence, is related to young women's body esteem. The first study examines the association between parents' sexist beliefs and their daughters' body esteem. The second study examines the associations between women's experiences as targets of sexism and their body esteem.

\section{Sexism directed towards women}

Ambivalent sexism theory (Glick \& Fiske, 1996, 2001a, 2001b) argues that sexism takes two forms, overt hostility and paternalistic benevolence. Hostile sexism involves negative attitudes that are directed toward women in nontraditional gender roles, such as career women and feminists. The hostility that sexist men express serves to show men's dominance and punish women who "step out of place" in regards to their gender roles. In contrast, heterosexual intimate interdependence results in many men idealizing women in traditional feminine roles: they cherish, adore, and act benevolently toward these women because these traditional relationships fulfill their dual desires for social dominance and intimacy. Thus, benevolent sexism reflects seemingly favorable responses to women who are in traditional gender roles. Despite their seemingly contradictory positive/negative attitudes towards women, research has consistently found that hostile and benevolent sexism are positively correlated (Glick \& Fiske, 
1996, 2001b). Indeed, endorsement of hostile and benevolent sexist beliefs are both correlated with support for gender inequality (Glick \& Fiske, 2001b).

\section{Benevolent Sexism and Women's Bodies}

A connection between ambivalent sexism and women's body esteem and appearance management was first proposed by Franzoi and Chang (2000), with an initial study by Franzoi (2001) indicating that women's endorsement of benevolent sexism was positively related to their sexual-attractiveness body esteem. Women's endorsement of benevolent sexism was also associated with use of cosmetic products prior to going on a date with a man, but not use of such products generally. Interestingly, Forbes et al. (2005) found that college women with high benevolent sexist beliefs were more likely than those with low levels of benevolent sexism to believe that other women of their age preferred larger sized bodies. Among the mothers of these same college women, benevolent sexism was positively correlated with their body esteem for weight and physical conditioning; however, this association was not found for the college daughters.

Cultural differences are also important to consider when studying this topic. For example, the association between benevolent sexism and body esteem and cosmetic use was stronger in a sample of Polish women than in an American sample, presumably because the overall sexism levels were higher in the Polish sample (Forbes, Doroszewicz, Card, \& Adams-Curtis, 2004). It should also be noted that contradictory findings were obtained by Swami et al. (2010) among a non-college community sample in Great Britain; benevolent sexism was negatively related to a general measure of body satisfaction. At present, it is unclear whether these inconsistent results are due to cultural, social class, or measurement differences with the original studies. 
Studies that have experimentally manipulated benevolent sexism find that it induces heightened body consciousness and appearance-management desires in women. Calogero and Jost (2011) found that after women read benevolently sexist statements on a questionnaire, they reported increased intention to engage in appearance management behavior than did women not exposed to such statements, consistent with Franzoi (2001) and Forbes et al. (2005) findings. However, experimental exposure to benevolent sexism was also associated with higher levels of body surveillance, self-objectification, and body shame. Similarly, Shepherd and her colleagues (2011) found that immediately after women witnessed an act of benevolent sexism-a man offering and a woman consenting to him carrying a box for her-they reported higher body surveillance and body shame (but not self-objectification) than women who did not witness this benevolently sexist act. While seemingly contradictory to the Franzoi and Forbes et al. studies, a key methodological difference is that both of these experimental studies manipulated exposure of benevolent sexism directed towards others rather than assessing self-endorsed or personallyexperienced sexism. A body of research demonstrates that women are better able to identify sexism when it is directed towards other women than if it is personally experienced (e.g., Crosby, 1984). This is especially likely to be the case for benevolent sexism engaged in by a loved one (such as father or romantic partner), which for many women is perceived as a desirable and rewarding interaction (e.g., Kilianski \& Rudman, 1998) even if it restricts their behaviors (Moya, Glick, Exposito, Lemus, \& Hart, 2007). Thus, observing benevolent sexism directed toward others is more likely to be identified as sexism and to result in different implications for body esteem than if it is personally endorsed or directly experienced during a social interaction.

\section{Hostile Sexism and Women's Bodies}


Hostile sexism is associated with punitive measures directed against women who are perceived as challenging male dominance and traditional gender roles (Glick \& Fiske, 1996). A number of feminist critics have argued that cultural body ideals serve as a weapon of oppression against women (e.g., Freedman, 1986; Jeffreys, 2005). Women who strive to attain the ultra-thin body ideal may receive conditional praise for working toward this illusive beauty standard (Bessenoff \& Del Priore, 2007; Posavac \& Posavac, 1998), but by internalizing this standard as an important basis for self-judgments they also become more susceptible to negative body esteem (Dohnt \& Tiggemann, 2006; Strahan, Wilson, Cressman, \& Buote, 2006), social anxiety related to their physical appearance (Park et al., 2009), and life-threatening illnesses associated with eating disorders (Martin, 2007). Internalizing this ultra-thin standard can also undermine women's feelings of social competence in interpersonal settings where they compete with men to wield social, economic, or political power (Fredrickson et al., 1998; Smith, 2008).

Consistent with this argument, Franzoi (2001) found that young women's hostile sexist beliefs were negatively related to their sexual attractiveness body esteem, while Forbes et al. (2005) found that for mothers, but not daughters, increases in hostile sexism were negatively associated with their body esteem. Furthermore, Forbes, Collinsworth, Jobe, Braun, \& Wise (2007) found that hostile sexism and hostility toward women, but not benevolent sexism, were positively correlated with the belief that it is important for women to be thin. Together, this research provides tentative support for the idea that hostile sexism is associated with women's body dissatisfaction.

In two studies we test the association between sexism, as expressed both with hostility and benevolence, and young women's body esteem. In Study 1, we examine how daughters', mothers' and father's ambivalent sexism is associated with young American women's body 
esteem. In Study 2, we investigate associations between young American women's body esteem and their self-reported experiences over the past year with both benevolent sexism and hostile sexism.

Study 1: Family-Based Sexism and Daughters’ Body Esteem

Because the family is one of the most important reference groups in shaping children's and adolescents' attitudes and beliefs about themselves and their social world (Steinberg \& Morris, 2001), we contend that parental endorsement of sexist beliefs will be related to their daughters' body esteem. Previous research has focused more on how mothers' attitudes and beliefs influence daughters' body image rather than on fathers' influence. These studies generally have found that mothers play a significant role in shaping daughters' body perceptions and body esteem (e.g., Clarke \& Griffin, 2007; Cooley, Toray, Wang, \& Valdez, 2008; Lowes \& Tiggemann, 2003). The relatively few studies that have examined fathers' influence generally find similar effects. Fathers who are preoccupied with weight issues in either themselves or their children tend to have daughters who express more negative attitudes toward their own weight and are more likely to induce vomiting to lose weight (Agras, Bryson, Hammer, \& Kraemer, 2007; Dixon, Gill, \& Adair, 2003). One thing to keep in mind regarding our present investigation is that we are not directly examining parental attitudes and beliefs concerning female physical appearance standards. Instead, our research is examining how parental benevolent and hostile sexism might be related to their daughters' body esteem.

Based on previous research by Franzoi (2001) and Forbes et al. (2005), we expect that familial endorsement of benevolent sexism will be positively associated with their daughter's body esteem. That is, parents who endorse these benevolently sexist beliefs are likely to interact with their daughters in ways that praise their traditional feminine qualities (including their looks) 
and lavish on them paternalistic warmth and adoration. This effect might be particularly strong when benevolent sexism is expressed by fathers given the heterosexual nature of ambivalent sexism (Glick \& Fiske, 1996) and because men have a stronger socializing influence for sexism than do women (Sibley et al., 2009). Furthermore, research on father-daughter relationships has identified a father subtype as the "doting father" (Perkins, 2001). This relationship is marked by a father who desires to keep his daughter childlike and within close proximity by using “disproportional personal and economic support" (pg. 619). This type of father provides adoring love to his "special little princess", but this infantalization is thought to ultimately weaken a daughter's own agency and assertiveness. Furthermore, young women tend to idealize their doting fathers and appear to have an overly strong identification with them, at the cost of their own identity development (Perkins, 2001). This type of father-daughter relationship appears to be high in benevolent sexism. While it is disconcerting that a father's benevolent sexism may be positively associated with his daughter's body esteem, it highlights the insidious nature of benevolent sexism. That is, these types of benevolent beliefs and behaviors are often unacknowledged as sexism and can have placating effects on women, even increasing positive moods (Becker \& Wright, 2011). However, these placating effects come at the cost of gender equality (Glick \& Fiske, 1996). In contrast, we speculate that mothers are less likely to engage in benevolently sexist behaviors with their daughters as they are more likely to be the recipients of this benevolently sexist praise. In sum, fathers' benevolent sexism is hypothesized to be more strongly related to their daughters' body esteem than mothers' similarly expressed sexism.

Regarding hostile sexism, we expect that when parents interact with their daughters they will be far more likely to express benevolent sexism rather than hostile attitudes. As such, we hypothesized that parents' hostile sexism will not have much influence on daughters' body 
esteem compared to benevolent sexism. While we don't expect parental hostile sexism to have an appreciable negative effect on daughters' body esteem, previous research suggests that young women's own hostile sexist beliefs may play a role in them evaluating their own bodies more harshly (Forbes et al., 2005; Franzoi, 2001). As suggested by Franzoi (2001), women who hold fellow women in low regard may develop similarly negative self-beliefs that make it difficult for them to feel good about their bodies. Thus, we hypothesized that daughters' hostile sexism would be negatively associated with their own body esteem.

\section{Method}

\section{Participants}

Eighty-six first-year female college students enrolled in an introductory psychology course at a mid-size Midwestern university participated in the study along with their parents. Daughters ranged in age from 18 to 19 years $(M=18.21, S D=.41)$. The vast majority of participants ( $87 \%$ of daughters, $96 \%$ of mothers, and $90 \%$ of fathers) listed their ethnicity as Caucasian/White. Four daughters and one father listed their ethnicity as African American. Three daughters, two mothers, and three fathers listed their ethnicity as Latino/a. Three daughters, one mother, and one father listed their ethnicity as Asian American. One daughter listed her ethnicity as Native American, and four daughters listed themselves as bi-racial. One daughter, one mother and two fathers listed themselves as citizens from another country, and one father and one daughter chose "other" to describe their ethnicity. Mothers' mean age was 49 years $(S D=3.50)$, father's mean age was 51 years $(S D=4.31)$.

\section{Measures}

Demographics. All participants were asked to complete basic demographic information on their gender, age and ethnicity. 
Ambivalent Sexism Inventory (ASI, Glick \& Fiske, 1997). The ASI investigates the degree of attitudes the participant has that support traditional feminine roles and characteristics (benevolent sexism), and those that display animosity toward women (hostile sexism). The scale consists of 22 items measured on a 6-point Likert scale $(0=$ Strongly disagree, $5=$ Agree strongly). The items were summed to form the subscales and higher numbers indicate more endorsement of hostile and benevolent sexist beliefs. For the daughters, the coefficient alphas for the benevolent and hostile subscales were .80 and .84 , respectively. For the fathers, the coefficient alphas for the benevolent and hostile subscales were .67 and .77 , respectively. For the mothers, the coefficient alphas for the benevolent and hostile subscales were .78 and .74, respectively.

Body Esteem Scale (BES, Franzoi \& Shields, 1984). The Body Esteem Scale was used to measure female body esteem, and consists of 35 body parts and functions rated on a 5-point Likert scale ranging from 1 (Have strong negative feelings) to 5 (Have strong positive feelings).. The items were summed and higher scores indicate more positive body-esteem for the three subscales: sexual attractiveness body esteem (e.g., lips, chest or breasts), weight-related body esteem (e.g., waist, thighs) and physical condition body esteem (e.g., muscular strength, biceps). The coefficient alphas were: sexual attractiveness body esteem: $\alpha=.81$; weight-related body esteem: $\alpha=.90$; physical condition body esteem: $\alpha=.80$.

\section{Procedure}

Participants completed the surveys as part of a larger study investigating student attitudes at the beginning and end of their first year in college. The data in the present study were collected at the end of the spring semester, with each student receiving ten dollars for their participation. To be included in the final analysis for this study, each student had to have both 
parents complete an online or paper survey. Parents completed the surveys at the beginning of their daughters' first semester in college. Parents were entered into a lottery drawing as a token of appreciation for their participation and their daughter received extra credit in their psychology course for each parent who participated. For the daughters who completed the spring assessment, sixty-nine college women had both mother and father who completed surveys.

\section{Results}

Table 1 reports the means, standard deviations, and intercorrelations among the variables in this study. In order to examine the relationship between college women's body esteem and parental and daughter ambivalent sexism, we conducted three separate regression analyses for the three dimensions of female body esteem (see Table 2). The multiple regression model for weight-related body esteem was significant, $F(6,61)=2.36, p=.04, \mathrm{R}^{2}=.19$. As predicted, fathers' benevolent sexism was significantly positively associated with daughters' positive weight-related body esteem, $(\beta=.30, p=.03)$. However, mothers' benevolent sexism was not a significant predictor, nor was mothers' and fathers' hostile sexism or daughters' benevolent and hostile sexism. The model for physical condition body esteem was marginally significant, $F(6$, $61)=1.99, p=.10, \mathrm{R}^{2}=.16$. As predicted, fathers' benevolent sexism $(\beta=.29, p=.03)$ was positively associated with self-evaluations of physical conditioning. However, as with weightrelated body esteem, no other measures were significant predictors. The regression model predicting daughters' sexual attractiveness body esteem was not significant, $F(6,61)=.71, p=$ $.64, \mathrm{R}^{2}=.07$.

\section{Discussion}

Study 1 results provided partial support for our hypotheses. We found that fathers who endorsed benevolent sexism were more likely to have daughters with positive body esteem, but 
no evidence suggested a similar influence for mothers' or daughters' benevolent sexist beliefs.

Fathers' benevolent sexism was positively associated with daughters' weight-related body esteem and physical conditioning body esteem, but not to sexual attractiveness body esteem. Together, these findings for fathers are consistent with the idea that a benevolently sexist family environment is associated with less body-related anxiety among daughters.

This finding, while expected based on previous literature, is also disconcerting. We imagine that most parents want to engage in behaviors that promote their daughter's body esteem and shield them from body dissatisfaction, eating disorders, and social physique anxiety. Benevolent sexism might initially appear to be a useful means to achieve such goals, yet benevolent sexism can also undermine young women's self-confidence to participate in both non-traditional activities and engage in collective action for gender-based social change (Becker \& Wright, 2011). A more empowering parental style is one in which fathers and mothers provide their daughters with support and praise for their efforts and goals without making such support contingent on paternalistic dependence. This parenting style should foster in young women both healthy body esteem and agency.

It is noteworthy that fathers' benevolent sexism predicted daughters' satisfaction with their weight and physical conditioning, but not toward body items related to sexual attractiveness. This lack of an association between fathers' sexist beliefs and daughters' sense of sexuality may be due to the fact that there are historically strong societal prohibitions against any sort of sexuality in father-daughter relationships. As such, it is reasonable to assume that normal father-daughter interactions should have less of an impact on daughters' evaluations of this aspect of their physical selves.

While the nonsignificant findings for mothers warrants further inquiry, it appears to be 
the case that daughters' body esteem is not directly related to mothers' adherence to benevolent or hostile sexist ideology. As we suspected, fathers' attitudes regarding the proper role of women in contemporary society appears to have a more significant association with their daughters' body esteem than mothers' comparable sexist attitudes (Sibley et al., 2009). Fathers who highly value the traditional feminine gender role may be more likely to lavish paternalistic warmth and praise on their daughters in a manner that boosts their daughters' sense of physical self-worth. In contrast, mothers with strong benevolent sexist attitudes may not interact with their daughters in the same paternalistic manner because they are accustomed to receiving, but not providing, such paternalistically-based warmth and praise. The non-significant findings for mothers do not necessarily mean that mothers' attitudes are unimportant. Research has generally found that mothers' attitudes and beliefs about female weight play a significant role in shaping daughters' body perceptions and body esteem (Clarke \& Griffin, 2007; Cooley et al., 2008; Hahn-Smith and Smith 2001; Lowes \& Tiggemann, 2003). Our findings may indicate that this influence is not directly related to mothers' adherence to benevolent or hostile sexist ideology.

Counter to expectations, daughters' benevolent and hostile sexism were not significantly related to their own body esteem. Previous research has been mixed regarding this relationship, with Franzoi (2001) finding these associations but Forbes et al. (2005) only finding an association between sexism and body esteem for mothers but not their daughters. As with the nonsignificant findings for mothers, it is possible that fathers' benevolently sexist beliefs are simply more important for setting the family context of sexism, and these beliefs overshadow the smaller influences of daughters' benevolent sexism. Alternatively, there might be a developmental issue in that college-aged women are forming their ideas about gender whereas older women have solidified their beliefs, thus making these ideologies more predictive with age. 
Hostile sexism was not related to daughters' body esteem. We speculate that parents are more likely to express sexism toward their daughters in a benevolent rather than in a hostile manner. However, outside the relatively benevolent confines of the family social environment, hostile sexism might exert a significant negative effect on women's body esteem. This possibility will be specifically examined in Study 2.

One limitation of the current study should be noted. The daughters' weight was not assessed in this first study. Previous research has found that body size is negatively related to body esteem and highlights the importance of controlling body mass index (BMI) when examining body esteem (Forbes et al., 2004). While we think it is unlikely, it is possible that thinner women are more likely to elicit benevolent sexism from their parents and other individuals in their social environment. In the second study we measure BMI to see if the proposed associations between hostile and benevolent sexism with body esteem remain after controlling for BMI.

\section{Study 2: Sexist Experiences and Women's Body Esteem}

Given that Study 1 found evidence that paternal expressions of benevolent sexism were positively associated with young adult daughters' weight-related and physical conditioning body esteem, Study 2 sought to determine whether young adult women's daily experiences with benevolent sexism and hostile sexism were similarly related to their body esteem. As previously noted, many people consider benevolently sexist behaviors as rewarding and socially desirable. It follows that being the recipient of benevolently sexist behaviors by men can result in an increased sense of body esteem for young women, mirroring the associations we found in Study 1 with fathers' benevolently sexist orientations. In Study 2 we hypothesized that the three 
dimensions of female body esteem would be positively correlated with women's self-reported experiences with benevolent sexism during the previous year.

Regarding hostile sexism, a growing body of research has shown that being the target of hostile sexist events is associated with a number of mental health issues (e.g., Klonoff \& Landrine, 1995; Landrine et al., 1995; Zucker \& Landry, 2007). It is relatively easy to imagine why being the social target of such gender-based hostility could negatively impact feelings of self-worth, including evaluations of the physical self. Thus, we hypothesized that the three dimensions of female body esteem would be negatively correlated with women's experiences with hostile sexism during the previous year.

\section{Method}

\section{Participants and Procedure}

A total of 246 college women attending a private Midwestern university received psychology course credit for their participation. Mean age was $19.10(S D=1.49)$, ranging from 18 to 31 . Mean body mass index (BMI: $\left.\mathrm{kg} / \mathrm{meters}^{2}\right)$ was $22.61(S D=3.45)$. The ethnic composition of the sample was largely Caucasian $(n=213,86.6 \%)$. Twelve individuals identified as African American, 11 identified as Latina, 11 identified as Asian American, and 11 as other ethnicities. There was little variability in the reported sexual orientation of participants: $84.6 \%$ reported heterosexual orientation, 1 person reported lesbian orientation, and $15 \%$ reported sexual orientation someplace between completely homosexual and completely heterosexual. Participants were recruited from psychology courses, with the vast majority coming from Introductory Psychology courses. Participant responses were collected as part of a larger survey. Materials 
Demographics. All participants were asked to complete basic demographic information on their gender, age, weight, height, and ethnicity.

Body Esteem Scale (Franzoi \& Shields, 1984). As in Study 1, the Body Esteem Scale (BES) was used to measure the three dimensions of female body esteem, with the resulting BES coefficient alphas for sexual attractiveness body esteem: $\alpha=.75$; weight-related body esteem: $\alpha$ $=.90 ;$ physical condition body esteem: $\alpha=.85$.

The Sexist Schedule of Events (Klonoff \& Landrine, 1995). The 20-item Sexist Schedule of Events (SSE) measures experiences with hostile sexism across a variety of domains, such as being sexually harassed, being told sexist jokes or experiencing degrading sex-related comments, and being treated unfairly because of one's sex. For this study, we utilized the SSERecent, which indicates the degree to which one experienced these hostile sexist events during the past year using a 6-point Likert scale $(1=$ The event never happened to $6=$ The event happened almost all of the time). The mean of the items was computed and higher numbers indicate more frequent sexism experiences. The coefficient alpha for the SSE-Recent measure was .88.

Experiences with Benevolent Sexism. A modified version of the Paternalistic Chivalry Scale (PCS: Viki, Abrams, \& Hutchison, 2003) was used to measure frequency of experiences with benevolent sexism during the past year. The 10-item PCS scale was originally developed to measure support for chivalrous behaviors that restrict women's control and roles in interpersonal relationships (e.g., "It is up to the man to decide where the couple is to have their dinner date.") “A woman cannot pay for the first date."). For the purpose of this study, PCS items were revised to measure frequency of actual experiences with chivalry behaviors using the same scale as the Sexist Schedule of Events-Recent $(1=$ The event never happened to $6=$ The event happened 
almost all of the time). The mean of the items was computed and higher numbers indicate more frequent benevolent sexism experiences. The coefficient alpha was .81

\section{Results}

Table 3 reports the means, standard deviations, and intercorrelations among the variables in this study. BMI correlated with weight-related body esteem $(r=-.46, p<.01)$, physical condition body esteem $(r=-.21, p<.01)$, but not with sexual attractiveness body esteem $(r=$ $.005, p=.94)$. BMI did not correlate significantly with reported benevolent sexist experiences ( $\mathrm{r}$ $=-.02, p=.71)$ or hostile sexist experiences $(r=.07, p=.30)$.

In order to examine the relationship between college women's ambivalent sexist experiences and their body esteem, we conducted three separate regression analyses for the three dimensions of female body esteem, controlling for BMI. The multiple regression model for weight-related body esteem was significant, $F(3,232)=23.64, p<.001, \mathrm{R}^{2}=.23$. As predicted, even after controlling for BMI $(\beta=-.44, p<.01)$, benevolent sexist experiences was positively associated with women's weight-related body esteem $(\beta=.16, p<.01)$, while hostile sexist experiences was marginally negatively correlated with weight-related body esteem, $(\beta=-.11, p=$ .06). Similarly, the multiple regression model for physical condition body esteem was significant, $F(3,232)=6.57, p=.001, \mathrm{R}^{2}=.08$, with benevolent sexist experiences being positively associated with women's physical condition body esteem, $(\beta=.14, p=.04)$ and hostile sexist experiences being negatively associated with this same body esteem dimension, $(\beta$ $=-.16, p=.02)$, even after controlling for BMI $(\beta=-.19, p<.01)$. Finally, the multiple regression model for sexual attractiveness body esteem was marginally significant, $F(3,232)=$ $2.19, p=.09, \mathrm{R}^{2}=.03$, but, as predicted, benevolent sexist experiences was positively associated with women's sexual attractiveness body esteem, $(\beta=.14, p=.04)$ and hostile sexist experiences 
was marginally negatively associated with this same body esteem dimension, $(\beta=-.11, p=.09)$, even after controlling for BMI $(\beta=.03, p=.63)$.

\section{Discussion}

The results of Study 2 are consistent with our theoretical reasoning, namely, that young women's experiences with benevolent sexism and hostile sexism have markedly different associations with their body esteem. Benevolent sexist experiences during the past year are positively correlated with women's weight-related body esteem, physical condition body esteem, and marginally positively correlated with their sexual attractiveness body esteem. In contrast, hostile sexist experiences during this same time period are negatively correlated with women's physical condition body esteem and marginally negatively correlated with both their weightrelated and sexual attractiveness body esteem dimensions. Thus, the current findings suggest that women who often encounter benevolently sexist experiences are more likely than other women to feel positively about their physical selves, while women who often encounter hostile sexist experiences are more likely than other women to feel negatively.

Notably, in this study we also assessed women's BMI (which is a function of height and weight). Importantly, BMI was not associated with reported hostile or benevolently sexist experiences. Thus, it does not appear as though women who are thinner are somehow inducing more sexist experiences from people they encounter socially. Furthermore, the contrasting associations between women's hostile and benevolently sexist experiences and their body esteem remain even after controlling for BMI.

\section{General Discussion}

The objective of the present investigation was to build upon the insights of a small handful of studies that sought to better understand the relationship between ambivalent sexism 
and female body esteem. Our findings not only provide greater clarity about the nature of this relationship, they also highlight how women's body-image issues can be better understood by distinguishing between two contrasting yet complementary forms of cultural sexism.

Consistent with a growing body of literature regarding the effects of sexual discrimination and hostile sexism on women's mental health (e.g., Landrine et al., 1995), we found that hostile sexism was negatively associated with all three dimensions of female body esteem. Hostile sexist experiences were defined as women experiencing and/or being forced to deal with overtly sexist behavior from various individuals, including teachers, employers, coworkers, strangers, family members, and boyfriends. Experiencing these types of events presents challenges for young women's mental well-being in a variety of areas including body esteem and eating disorders (Harned \& Fitzgerald, 2002; Klonoff \& Landrine, 1995; Landrine et al., 1995). As such, it is important for women, especially young women who are at heightened risk for body esteem issues and other mental health issues, to learn how to effectively cope with and respond to hostile sexist beliefs and sex discrimination.

While experiencing hostile sexist behaviors from others was associated with lower body esteem, parental hostile sexism was not associated with daughters' body esteem. As previously discussed, this latter finding is not surprising because one would not expect parents to express high levels of hostile sexism toward their daughters. This is not to say that parental hostile sexism is not potentially harmful to daughters; clearly, these messages could indirectly shape many of their attitudes and life experiences. However, we did not find a direct association between parental hostile sexism and daughter's body esteem.

Although sexism is commonly experienced and conceived of as entailing overtly negative attitudes and behaviors towards women, the more subtle benevolent sexism reflects a warm, 
paternalistic stance toward women who engage in gender traditional behaviors (Glick \& Fiske, 1996). Many social scientists contend that the socially acceptable "velvet glove" approach of benevolent sexism is more insidious than the blatant and less socially acceptable expressions of hostile sexism because women are less likely to recognize and challenge it as sexism, and thus, willingly participate in its perpetuation (Kilianski \& Rudman, 1998; Moya et al., 2007). Indeed, while hostile sexism is easily identified as discrimination and often serves as a catalyst for collective action, benevolent sexism is often welcomed by women and decreases their efforts at seeking social change (Becker \& Wright, 2011). In essence, benevolent sexism can seduce women into accepting male dominance.

The most important findings in Study 1 involve the associations observed between daughters' body esteem and fathers' attitudes and beliefs about benevolent sexism. This association presumably occurs because fathers who hold strong benevolent sexist beliefs are more likely to express patronizing paternalistic warmth during their daughters' formative years of childhood and adolescence. Furthermore, we suspect that households with such parents are likely to encourage their daughters to engage in behaviors such as cosmetic use, concern for clothing and other gendered behaviors that are designed to highlight and flatter traditional feminine appearance. In the second study we found further evidence that female body esteem was positively related to women being treated in a benevolently sexist manner during the previous year, while simultaneously being negatively related to being treated in a hostilely sexist manner.

One straightforward way to interpret these findings is that women's body esteem is enhanced when they are treated by men as "special" people who should be put on a pedestal, while their body esteem is undermined when they are treated in a hostile manner, as people who lack value. Because physical appearance is a culturally defining characteristic for many women, 
their degree of body esteem is likely affected by how positively or negatively others treat them. This interpretation is in line with research indicating that women are more likely than men to be judged based on their physical appearance (Davis, 1990).

While straightforward explanations are generally very appealing, decades of research inform us that cultural sexism is anything but straightforward. For this important reason, positive and negative treatment of women needs to be understood through a gendered lens. Our findings suggest that female body esteem appears to be associated with women being treated in a culturally perceived and gender-typed positive manner, yet such treatment also implies a subservient gender role for these women. This is a concerning association as benevolent sexism has a number of negative implications for women. Women's acceptance and approval of benevolently sexist beliefs and behaviors will ultimately undermine their long term body esteem and mental health because the positive association between benevolent sexism and young women's body esteem is both fleeting and decidedly conditional. Benevolent sexism is only bestowed upon women in gender traditional, subservient roles. Upon stepping out of that socially approved role, women will be targeted with hostile sexism by the same individuals who initially bestowed upon them benevolent sexism (Glick \& Fiske, 2001a, 2001b). Thus any "benefit" to women's body esteem comes at a cost of gender equality and can be withdrawn. The better we understand how these gender-based benefits operate in the lives of women, the better we will understand the social psychological underpinnings of young women's body esteem and mental health.

Overall, these findings are consistent with our hypotheses and a body of research on ambivalent sexism and body esteem (e.g., Franzoi, 2001; Forbes et al., 2004; 2005), yet some might claim possible inconsistencies with two recent studies on sexism and body issues (e.g., 
Calogero \& Jost, 2011; Shepard et al., 2011). As already noted, the Calogero and Jost (2011) and Shepard et al. (2011) studies, unlike our study, were experimental in nature, examining how women felt "in the moment" about their bodies after witnessing benevolent sexism toward another woman. Also unlike our study, these two studies did not measure body esteem but rather body surveillance and body shame. While these constructs are related to body esteem, there are key theoretical differences, especially with body shame. For example, body shame specifically measures people's tendency to evaluate themselves negatively in situations where they fail to maximize their body's appeal as a beauty object, given their "natural beauty." In contrast, body esteem assesses people's self-evaluations of specific body dimensions that are very likely based on a combination of personal and cultural factors, only one of which might be shame over not adequately taking the time to look one's best. Given these key differences in the research methods and body measure employed in these studies, we do not necessarily see the results as inconsistent, but as highlighting the complexity of the relationship between sexism and how women feel about their bodies.

\section{Clinical implications}

Body esteem has been an essential guide to understanding the impact of numerous mental health issues, including eating disorders, depression, and anxiety (Biby, 1998; Davis, Brewer, \& Weinstein, 1993; Ferguson et al., 2011; Striegel-Moore, Silberstein \& Rodin, 1993). For example, weight concern and other aspects of body evaluation are important components for understanding eating disorders, including anorexia, bulimia, and binge eating (Davis, 1997; Davis et al., 1993; Davis, Kaptein, Kaplan, Olmsted, \& Woodside, 1998; Kaminski \& McNamara, 1996; Rieder \& Ruderman, 2001; Striegel-Moore et al., 1993; Tassava \& Ruderman, 1999). Additionally, in a sample of adolescents, individuals who reported higher levels of 
depression also reported lower levels of body esteem (Jonsdottir, Arnarson, \& Smari, 2008). In explaining this association, the researchers stressed the importance that body esteem has to overall psychological well-being, and suggested that promoting positive body esteem is integral in treating depression.

If mental health practitioners hope to gain adequate understanding of women's mental health issues, it is essential that they understand women's experiences in society and the broad cultural context in which mental health problems develop. With that goal in mind, our current results highlight the importance of practitioners being aware of cultural sexism in all its complexity when treating women with body esteem and related disorders. Current clinical strategies for dealing with such problems focus on education, resisting unhealthy media messages, promotion of healthy eating, and self-esteem enhancement. Building upon this current foundation of treatment, mental health professionals should endeavor to become even more aware of their female clients' own beliefs regarding gender and sexism, as well as the beliefs originating from family, friends, and the larger society. Furthermore, it is important to teach young women in a therapeutic setting how to effectively deal with hostile and benevolent sexism in order to support their sense of self-worth in all domains of life. This is especially important given the difficult task women often have in responding to sexist behaviors and comments in their everyday lives (Swim \& Hyers, 1999).

\section{Study limitations and future research directions}

These two studies together highlight the importance of taking into account culturally based sexist ideologies when examining women's body esteem. However, due to the correlational nature of the data, drawing clear causal connections between sexism and young women's body esteem is admittedly speculative. Although it is highly unlikely that daughters 
with positive body esteem somehow cause heightened benevolent sexist beliefs in their fathers and others, it is possible that the significant correlation between these two variables is caused by an unmeasured third variable. Cultural sexism is a complex social phenomenon, and therefore, additional research is necessary to rule out a third-variable explanation. Second, it is unclear if the association between benevolent sexism and body esteem extends to a more general level of self-esteem. In this paper we focus on women's body esteem, but future research should also examine general self-esteem issues. A third limitation of the current investigation is that it took place at a Midwestern, predominately White, Catholic University. Additional research with diverse samples is warranted. Finally, longitudinal research is essential for understanding the long-term consequences of exposure to sexist attitudes and behaviors.

\section{Summary}

Cultural sexism permeates modern American society, despite the many gains of women in the workforce and their personal lives. Being exposed to sexist beliefs and behaviors has the potential to shape women's body-esteem, sense of self-worth, and mental wellbeing. We hope this research highlights the complexity of these cultural beliefs and encourages researchers and clinicians to take this wider cultural context into consideration when examining and treating women's body esteem issues. 


\section{References}

Agras, W. S., Bryson, S., Hammer, L. D., \& Kraemer, H. C. (2007). Childhood risk factors for thin body preoccupation and social pressure to be thin. Journal of the American Academy of Child \& Adolescent Psychiatry, 46, 171-178.

Becker, J. C., \& Wright, S. C. (2011). Yet another dark side of chivalry: Benevolent sexism undermines and hostile sexism motivates collective action for social change. Journal of Personality and Social Psychology, 101, 62-77.

Bessenoff, G. R., \& Del Priore, R. E. (2007). Women, weight, and age: Social comparison to magazine images across the lifespan. Sex Roles, 56, 215-222.

Biby, E. L. (1998). The relationship between body dysmorphic disorder and depression, selfesteem, somatization, and obsessive-compulsive disorder. Journal of Clinical Psychology, 54, 489-499.

Britton, L.E., Martz, D.M., Bazzini, D.G., Curtin, L.A., \& LeaShomb, A. (2006). Fat talk and self-presentation of body image: Is there a social norm for women to self-degrade? Body Image, 3, 247-254.

Brown, A., \& Dittmar, H. (2005). Think "thin" and feel bad: The role of appearance schema activation, attention level, and thin-deal internalizations for young women's responses to ultra-thin media ideals. Journal of Social and Clinical Psychology, 24, 1088-1113.

Bruch, H. (1973). Eating disorders. Obesity, anorexia nervosa, and the person within. New York: Basic Books.

Calogero, R. \& Jost, J. (2011). Self-subjugation among women: Exposure to sexist ideology, self-objectification, and the protective function of the need to avoid closure. Journal of Personality and Social Psychology, 100, 211-228. 
Clarke, L. H., \& Griffin, M. (2007). Becoming and being gendered through the body: Older women, their mothers and body image. Ageing \& Society, 27, 701-718.

Coomber, K., \& King, R. M. (2008). The role of sisters in body image dissatisfaction and disordered eating. Sex Roles, 59, 81-93.

Cooley, E., Toray, T., Wang, M. C., \& Valdez, N. N. (2008). Maternal effects on daughters' eating pathology and body image. Eating Behaviors, 9, 52-61.

Crosby, F., (1984). The denial of personal discrimination. American Behavioral Scientist, 27, 371-386.

Davis, S. (1990). Men as success objects and women as sex objects: A study of personal advertisements. Sex Roles, 23, 43-50.

Davis, C. (1997). Normal and neurotic perfectionism in eating disorders: an interactive model. International Journal of Eating Disorders, 22, 421-426.

Davis, C., Brewer, H., \& Weinstein, M. (1993) A study of appearance anxiety in young men. Social Behavior and Personality, 21, 63-74.

Davis, C., Kaptein, S., Kapla, A. S., Olmsted, M. P., \& Woodside, D. B. (1998) Obsessionality in anorexia nervosa: the moderating influence of exercise. Psychosomatic Medicine, 60, 192-197.

Dittmar, H. (2009). How do "body perfect" ideals in the media have a negative impact on body image and behaviors? Factors and processes related to self and identity. Journal of Social and Clinical Psychology, 28, 1-8.

Dittmar, H., \& Howard, S. (2004). Ideal-body internalization and social comparison tendency as moderators of thin media models' impact on women's body-focused anxiety. Journal of Social and Clinical Psychology, 23, 747-770. 
Dixon, R. S., Gill, J. M. W., \& Adair, V. A. (2003). Exploring paternal influences on the dieting behaviors of adolescent girls. Eating Disorders: The Journal of Treatment \& Prevention, $11,39-50$.

Dohnt, H., \& Tiggemann, M. (2006). The contribution of peer and media influences to the development of body satisfaction and self-esteem in young girls: A prospective study. Developmental Psychology, 42, 929-936.

Feingold, A., \& Mazzella, R. (1998). Gender differences in body image are increasing. Psychological Science, 9, 190-195.

Ferguson, C. J., Munoz, M. E., Contreras, S. \& Velasquez, K. (2011). Mirror, mirror on the wall: Peer competition, television influences, and body image dissatisfaction. Journal of Social and Clinical Psychology, 30, 458-483.

Forbes, G. B., Adams-Curtis, L., Jobe, R. L., White, K. B., Revak, J., Zivcic-Becirevic, I., \& Pokrajac-Bulian, A. (2005). Body dissatisfaction in college women and their mothers: Cohort effects, developmental effects, and the influences of body size, sexism, and the thin body ideal. Sex Roles, 53, 281-298.

Forbes, G. B., Collinsworth, L. L., Jobe, R. L., Braun, K. D., \& Wise, L. M. (2007). Sexism, hostility toward women, and endorsement of beauty ideals and practices: Are beauty ideals associated with oppressive beliefs? Sex Roles, 56, 265-273.

Forbes, G. B., Doroszewicz, K., Card, K., \& Adams-Curtis, L. (2004). Association of the thin body idea, ambivalent sexism, and self-esteem with body acceptance and the preferred body size of college women in Poland and the United States. Sex Roles, 50, 331-345.

Franzoi, S. L. (2001). Is female body esteem shaped by benevolent sexism? Sex Roles, 44, 177188. 
Franzoi, S. L., \& Chang, Z. (2000). The sociocultural dynamics of the physical self: How does gender shape body esteem? In J. A. Holstein \& G. Miller (Eds.), Perspectives on social problems, Vol. 12, pp. 179-201. Stamford, CT: JAI Press.

Franzoi, S. L., \& Shields, S. A. (1984). The body esteem scale: Multidimensional structure and sex differences in a college population. Journal of Personality Assessment, 48, 173-178.

Franzoi, S. L., Vasquez, K., Sparapani, E., Frost, K., Martin, J., \& Aebly, M. (2012). Exploring body comparison tendencies: Women are self-critical whereas men are self-hopeful. Psychology of Women Quarterly, 36, 99-109.

Fredrickson, B. L., Roberts, T., Noll, S. M., Quinn, D. M., \& Twenge, J. M. (1998). That swimsuit becomes you: Sex differences in self-objectification, restrained eating, and math performance. Journal of Personality and Social Psychology, 75, 269-284.

Freedman, R. (1986). Beauty bound. Lexington, MA: Lexington Books.

Gapinski, K. D., Brownell, K. D., \& LaFrance, M. (2003). Body objectification and "fat talk": Effects on emotion, motivation, and cognitive performance. Sex Roles, 48, 377-388.

Glick, P., \& Fiske, S. T. (1996). The ambivalent sexism inventory: Differentiating hostile and benevolent sexism. Journal of Personality and Social Psychology, 70, 491-512.

Glick, P., \& Fiske, S. (1997). Hostile and benevolent sexism: Measuring ambivalent sexist attitudes toward women. Psychology of Women Quarterly, 21, 119-136.

Glick, P., \& Fiske, S. T. (2001a). Ambivalent sexism. In M. P. Zanna (Ed.), Advances in experimental social psychology. (pp. 115-188). San Francisco: Academic Press.

Glick, P., \& Fiske, S. T. (2001b). An ambivalent alliance. Hostile and benevolent sexism as complementary justifications for gender inequality. American Psychologist, 56, 109-118.

Grabe, S., Ward, L. M., Hyde, J. S. (2008). The role of the media in body image concerns among 
women: A meta-analysis of experimental and correlational studies. Psychological Bulletin, 134, 460-476.

Gravener, J. A., Haedt, A. A., Heatherton, T. F., \& Keel, P. K. (2008). Gender and age differences in associations between peer dieting and drive for thinness. International Journal of Eating Disorders, 41, 57-63.

Grogan, S. (2008). Body image: Understanding body dissatisfaction in men, women, and children. New York: Routledge.

Hahn-Smith, A. M., \& Smith, J. E. (2001). The positive influence of maternal identification on body image, eating attitudes, and self-esteem of Hispanic and Anglo girls. International Journal of Eating Disorders, 29, 429-440.

Harned, M. S., \& Fitzgerald, L. F. (2002). Understanding a link between sexual harassment and eating disorder symptoms: A meditational analysis. Journal of Consulting and Clinical psychology, 70, 1170-1181.

Jeffreys, S. (2005). Beauty and misogyny: Harmful cultural practices in the West. New York, NY: Routledge.

Jonsdottir, S. R., Arnarson, E. O., \& Smari, J. (2008). Body esteem, perceived competence and depression in Icelandic adolescents. Nordic Psychology, 60, 58-71.

Kaminski, P. L., \& McNamara, K. (1996). A treatment for college women at risk for bulimia: A controlled evaluation. Journal of Counseling and Development, 74, 288-294.

Kilianski, S., \& Rudman, L. A. (1998). Wanting it both ways: Do women approve of benevolent sexism? Sex Roles, 39, 333-352.

Klonoff, E. A., \& Landrine, H. (1995). The Schedule of Sexist Events: A measure of lifetime and recent sexist discrimination in women's lives. Psychology of Women Quarterly, 19, 439- 
472.

Landrine, H., Klonoff, E. A., Gibbs, J., Manning, V., \& Lund, M. (1995). Physical and psychiatric correlates of gender discrimination. Psychology of Women Quarterly, 19, 473492.

Lowes, J., \& Tiggemann, M. (2003). Body dissatisfaction, dieting awareness and the impact of parental influence in young children. British Journal of Health Psychology, 8, 135-147.

Martin, C. E. (2007). Perfect girls, starving daughters: The frightening new normalcy of hating your body. New York: Free Press.

Moya, M., Glick, P., Exposito, F., Lemus, S., \& Hart, J. (2007). It’s for your own good: Benevolent sexism and women's reactions to protectively justified restrictions. Personality and Social Psychology Bulletin, 33, 1421-1434.

Park, L. E. (2007). Appearance-based rejection sensitivity: Implications for mental and physical health, affect, and motivation. Personality and Social Psychology Bulletin 33, 490-504.

Park, L. E., DiRaddo, A. M., \& Calogero, R. M. (2009). Sociocultural influence and appearancebased rejection sensitivity among college students. Psychology of Women Quarterly, 33, 108-119.

Perkins, R. M. (2001). The father-daughter relationship: Familial interactions that impact a daughter's style of life. College Student Journal, 35, 616- 626.

Polivy, J., \& Herman, C. P. (2004). Sociocultural idealization of thin female body shapes: An introduction to the special issues on body image and eating disorders. Journal of Social and Clinical Psychology, 23, 1-6.

Posavac, H. D., \& Posavac, S. S. (1998). Exposure to media images of female attractiveness and concern with body weight among young women. Sex Roles, 38, 187-201. 
Rieder, S., \& Ruderman, A. (2001). Cognitive factors associated with binge and purge eating behaviors: The interaction of body dissatisfaction and body image importance. Cognitive Therapy and Research, 25, 801-812.

Shepherd, M., Erchull, M., J., Rosner, A., Taubenberger, L., Queen, E. F., \& McKee, J. (2011). "I'll get that for you": The relationship between benevolent sexism and body selfperceptions. Sex Roles, 64, 1-8.

Sibley, C. G., Overall, N. C., Duckitt, J., Perry, R., Milfont, T. L., Khan, S. S., Fischer, R., \& Robertson, A. (2009). Your sexism predicts my sexism: Perceptions of men's (but not women's) sexism affects one's own sexism over time. Sex Roles, 60, 682-693.

Smith, C. A. (2008). Women, weight, and body image. In J. C. Chrisler, C. Golden, \& P. D. Rozee (Eds.). Lectures on the psychology of women (4th ed.). pp. 117-135. New York: McGraw-Hill.

Steinberg, L., \& Morris, A. S. (2001). Adolescent development. Annual Review of Psychology, 52, 83-110.

Strahan, E. J., Wilson, A. E., Cressman, K. E., \& Buote, V. M. (2006). Comparing to perfection: How cultural norms for appearance affect social comparison and self-image. Body Image, $3,211-227$.

Striegel-Moore, R. H., Silberstein, L. R., \& Rodin, J. (1993). The social self in bulimia nervosa: public self-consciousness, social anxiety, and perceived fraudulence. Journal of Abnormal Psychology, 102, 297-303.

Swami, V., Coles, R., Wilson, E., Salem, N., Wyrozumski, K., \& Furnham, A. (2010). Oppressive beliefs at play: Associations among beauty ideals and practices and individual 
differences in sexism, objectification of others, and media exposure. Psychology of Women Quarterly, 34, 365-379.

Swim, J., \& Hyers, L. (1999). Excuse me - what did you just say?: Women's public and private response to sexist remarks. Journal of Social and Experimental Psychology, 35, 68-88.

Tassava, S., \& Ruderman, A.J. (1999). Application of escape theory to binge eating and suicidality in college women. Journal of Social and Clinical Psychology, 18, 450-466.

Tiggemann, M. (2010). Mental health risks of self-objectification: A review of the empirical evidence for disordered eating, depressed mood, and sexual dysfunction. In R. M. Calogero, S. Tantleff-Dunn, \& J. K. Thompson (Eds.), Objectification of women: Innovative directions in research and practice. Washington, D.C.: American Psychological Association.

Tiggeman, M., \& McGill, B. (2004). The role of social comparison in the effect of magazine advertisements on women's mood and body esteem. Journal of Social and Clinical Psychology, 23, 23-44.

Viki, G. T., Abrams, D., \& Hutchinson, P. (2003). The "true" romantic: Benevolent sexism and paternalistic chivalry. Sex Roles, 49, 533-537.

Zucker, A. N., \& Landry, L. J. (2007). Embodied discrimination: The relation of sexism to women's drinking and smoking behaviors. Sex Roles, 56, 193-203. 
Table 1. Sexism and Body Esteem Subscale Correlation Matrix

\begin{tabular}{lccc}
\hline Subscale $(\mathrm{N}=68)$ & Sexual Attractiveness & Weight-related & Physical Condition \\
$\mathrm{M}(\mathrm{SD})$ & Esteem & Esteem & Esteem \\
& $47.25(6.62)$ & & $33.21(6.06)$ \\
& $31.04(8.29)$ &
\end{tabular}

Daughter Hostile Sexism

$-.07$

.15

.06

$23.79(9.60)$

Daughter Benevolent Sexism

$-.02$

$-.04$

.11

$27.22(8.58)$

Mother Hostile Sexism

$-.02$

.22

.21

$24.25(7.54)$

Mother Benevolent Sexism

.20

.08

$.26 *$

$24.76(9.10)$

Father Hostile Sexism

.02

$.29 *$

.05

$27.91(7.94)$

Father Benevolent Sexism

.18

$.30 *$

$.30 *$

31.15 (7.36)

Note: $*$ indicates $p<.05$ 
Table 2. Multiple Regressions for Parent and Daughter Ambivalent Sexism Variables Predicting Daughters' Body Esteem

\section{Variable}

Weight-related Esteem

Daughter's Hostile Sexism

.17

Daughter's Benevolent Sexism

Mother's Hostile Sexism

Mother's Benevolent Sexism

Father's Hostile Sexism

Father's Benevolent Sexism

$F(6,61)=2.36, p=.04$

Sexual Attractiveness Esteem

Daughter's Hostile Sexism

Daughter's Benevolent Sexism

Mother's Hostile Sexism

Mother's Benevolent Sexism

Father's Hostile Sexism

Father's Benevolent Sexism

$F(6,61)=0.71$, n.s.
.02

$-.04$

$-.05$

.12

$-.02$

.12

.11
.17

$-.13$

.11

$-.02$

.16

$.30 *$

\section{$\beta$}

.15

.16 


\begin{tabular}{lccc} 
Mother's Hostile Sexism & .16 & .13 & .16 \\
Mother's Benevolent Sexism & .13 & .11 & .16 \\
Father's Hostile Sexism & -.11 & .12 & -.12 \\
Father's Benevolent Sexism & .29 & .13 & $.29 *$ \\
$F(6,61)=1.99, p=.08$ & & & \\
\hline
\end{tabular}

Note. $*$ indicates $p<.05$ 
Table 3. Experiencing Sexism and Body Esteem, Means and Correlations

\begin{tabular}{lccc}
\hline Subscale & Sexual & Weight-related & Physical Condition \\
& Attractiveness & & \\
M (SD) & $43.20(6.01)$ & $29.81(9.12)$ & $31.20(6.57)$ \\
\hline Hostile sexist experience & -.08 & $-.12^{*}$ & $-.15^{* *}$ \\
$1.87(.60)$ & & & $.11^{*}$ \\
Paternalistic sexist experience & $.11^{*}$ & & \\
$3.51(.96)$ & & & \\
\end{tabular}

Note: $*$ indicates $p<.10, * * p<.01$ 